\title{
Autonomic dysfunction (sweating responses) in multiple sclerosis
}

\author{
M. J. NORONHA, C. J. VAS, AND H. AZIZ \\ From the Neurological Departments of the General Infirmary at Leeds and \\ Pinderfields General Hospital, Wakefield
}

Bladder disturbances and sexual impotence are common and distressing disorders occurring in multiple sclerosis. Miller, Simpson, and Yeates (1965) found bladder complaints occurring at some time of the disease in $78 \%$ of 297 patients, and in $52 \%$ of them it had persisted for over six months, while sexual impotence due to physical disease occurred in $44 \%$ of their patients. Although these disturbances are known to arise from involvement of peripheral or central autonomic pathways (Kuntz, 1947; Bors and Comarr, 1960), the lesions of multiple sclerosis are restricted to the central nervous system and consequently they must arise from disruption of central pathways. To our knowledge no specific study has been made on autonomic dysfunction occurring in multiple sclerosis.

We have, accordingly, investigated the sympathetic nervous system in this disease by means of eliciting the sweating responses to heat, to drugs, and to distension of the urinary bladder, since these procedures are easy to carry out and can be repeated with consistent results.

\section{METHOD}

Practically all the subjects studied were already in our controlled trial which has been going on for over three years, and in which we are investigating the therapeutic value of the long-term administration of A.C.T.H. Gel in multiple sclerosis. No patient was known to have suffered from any generalized skin disease which may have affected their sweating responses (Sulzberger and Herrmann, 1954).

THERMOREGULATORY SWEATING This procedure has been described by Guttmann (1947) and was used routinely to induce sweating in 60 patients of whom 45 were female and 15 male. After the patient had ingested hot fluids (a cup of tea) and $10 \mathrm{gr}$. acetylsalicylic acid, the trunk was heated by means of a heat cradle. The subject and heat cradle were covered with blankets leaving only the head and neck exposed. The patient was sprayed with quinzarin powder in order to detect the area of sweating. This powder, normally grey in colour, changes to a deep blue when sweating occurs. The intensity and the distri- bution of the change in colour gives a rough estimate of the amount of perspiration that has taken place. The procedure was carried out with the subject lying in the supine position, since it is known that postural reflexes can modify the sweating responses (Kuno, 1956).

Skin temperatures of the forehead, trunk, and proximal and distal limbs were registered with an electric universal thermometer, and oral temperatures with an ordinary clinical thermometer, at the commencement and the completion of the test.

DRUG-INDUCED SWEATING Twenty-two patients, 10 with normal and 12 with abnormal thermal sweating responses, received $7.5 \mathrm{mg}$ pilocarpine intravenously and the distribution and extent of sweating was observed.

SPINAL REFLEX SWEATING Seven patients with bladder disturbances and impaired thermal sweating responses were also investigated for the presence of spinal reflex sweating, (Head and Riddoch, 1917; List and Pimenta, 1944; Guttmann and Whitteridge, 1947). After cystoscopy, the bladder was catheterized and gradually distended with sterile water until the patient felt discomfort and a desire to void urine. The catheter was then clamped, and left in situ for periods up to $\mathbf{3 0} \mathrm{min}$ or until such time as the patient could no longer tolerate the discomfort of the bladder distension.

CLINICAL SCORING As these patients were being examined regularly and scored clinically according to the system described by (Kurtzke, 1961), we have compared the results of their thermal sweating responses with their clinical scores. Because we felt that the original method of Kurtzke scoring did not correlate well with the variation in the clinical state of the patient we have accordingly modified it.

POSTURAL HYPOTENSION These patients were questioned about the presence of postural hypotension, and those who were able to stand had their blood pressures recorded in the supine and erect positions.

\section{RESULTS}

THERMOREGULATORY SWEATING RESPONSES (Table I). Normal thermal sweating responses occurred in 35 patients. Sweating initially commenced on the 
TABLE I

THERMOREGULATORY SWEATING RESPONSES

$\begin{array}{lrc} & \text { Results } \\ & \text { No. } & \% \\ \text { Total Patients } & 60 & \\ \text { Females } & 45 \\ \text { Males } & 15 & \\ & & \\ \text { Normal thermoregulatory responses } & 35 & 58 \\ \text { Abnormal thermoregulatory responses } & 25 & 42 \\ \text { Total anhydrosis } & 2 & 3.5 \\ \text { Facial sweating only } & 2 & 3.5 \\ \text { Absence of sweating below waist } & 7 & 12 \\ \text { Absence of sweating below groins } & 14 & 23\end{array}$

forehead and chest and quickly spread to the remainder of the trunk and later to the limbs as well. Twenty-five subjects were considered to have impaired thermal sweating responses. In two patients there was total lack of sweating apart from some contact sweating occurring in the axillae and groins, while in another two sweating was present only over the face. In seven sweating was absent below the waist and in 14 it was absent over the lower limbs only.

The average increase in oral temperature (Table 2) was $1.7^{\circ} \mathrm{F}$ in the normals, and $2.2^{\circ} \mathrm{F}$ in the abnormals, and in the feet $5.7^{\circ} \mathrm{F}$ in the normals,

\section{TABLE II}

TEMPERATURE CHANGES $\left({ }^{\circ} \mathrm{F}\right)$

\begin{tabular}{|c|c|c|c|c|}
\hline & \multicolumn{2}{|c|}{$\begin{array}{l}\text { Oral Temperature } \\
\text { Increase }\left({ }^{\circ} \mathrm{F}\right)\end{array}$} & \multicolumn{2}{|c|}{$\begin{array}{l}\text { Feet Temperature }\left({ }^{\circ} \mathrm{F}\right) \\
(\text { Mean })\end{array}$} \\
\hline & Mean & Range & $\begin{array}{l}\text { Before } \\
\text { Heating }\end{array}$ & $\begin{array}{l}\text { After } \\
\text { Heating }\end{array}$ \\
\hline $\begin{array}{l}\text { Normal sweating } \\
\text { response (35) }\end{array}$ & 1.7 & $(0.4-3 \cdot 6)$ & 29.9 & $35 \cdot 6$ \\
\hline $\begin{array}{l}\text { Abnormal sweating } \\
\text { response (25) }\end{array}$ & $2 \cdot 2$ & $(0.6-3.8)$ & $28 \cdot 9$ & $37 \cdot 2$ \\
\hline
\end{tabular}

and $8.3^{\circ} \mathrm{F}$ in the abnormals. In the regions of absent sweating erythema was practically always observed.

At the completion of the period of heating nearly all the subjects noticed a temporary aggravation of their symptoms, but this was reversed within a few hours when their body temperatures had returned to normal levels (Edmund and Fog, 1955; Nelson and McDowell, 1959).

The incidence of abnormal sweating responses was much higher in the patients with more severe and advanced multiple sclerosis (Table III). This was most striking when the results of the overale Kurtzke disability and pyramidal scores are com-D pared, but this difference was much less marked with bladder dysfunction.

DRUG-INDUCED SWEATING Intravenous pilocarpine was successful in increasing the amount of sweating in 20 of the 22 subjects. This increase tended to be maximal on the upper trunk but its effect on the lower trunk and lower limbs was usually very slight: or absent (List and Peet, 1938; Hyndman and Wolkin, 1941b). The action of pilocarpine on sweating is mainly peripheral by stimulation of sympathetic cholinergic nerve endings (Dale and $\overline{\bar{c}}$ ) Feldberg, 1934).

The two patients who failed to respond to the pilocarpine had also shown a total lack of response $e^{\infty}$ to thermal sweating. Both of them are males ando suffer from fairly advanced multiple sclerosis.

The first man (M.W.), 25 years old, used to $\omega_{\sigma}$ perspire profusely as he worked in a blast furnace. $\overline{3}$ Ten months previously he had stopped working as his clinical condition had deteriorated due tow numerous exacerbations of the multiple sclerosis.:Over the past six months he had noticed complege $\overrightarrow{0}$ absence of sweating, and this had been associat $\mathrm{d}_{0}$ with the onset of failure of emission of seming $1^{-}$ fluid, despite the ability to have normal sexuat 1 intercourse with satisfactory orgasms.

The other man (R.S.), aged 39 years, perspiredd normally until his condition deteriorated three years ago. Since then he had noticed a progressize inability to sweat, associated with total sexualo impotence, and urgency of micturition with frequent ${ }^{\circ}$ urinary incontinence.

Most of these patients experienced the following side-effects consequent on the administration of pilocarpine: salivation, lacrimation, dyspnoea, vomiting, and a desire to micturate.

SPINAL REFLEX SWEATING Spinal reflex sweating 3 was absent in all seven patients investigated by means of distension of the urinary bladder. Four of these? patients were suffering from advanced multiple sclerosis with severe cerebellar and pyramidal signs $\frac{2}{0}$ in the legs. Six patients were able to tolerate the distended bladder for a period of $\mathbf{3 0} \mathrm{min}$ but in one $\mathrm{S}$.

TABLE III

ABNORMAL SWEATING RESPONSES IN REACTION TO SEVERITY OF MULTIPLE SCLEROSIS (MEAN VALUES)

\begin{tabular}{|c|c|c|c|c|c|c|}
\hline & $\begin{array}{l}\text { Kurtzke } \\
\text { Disability } \\
\text { Status Scale }\end{array}$ & Pyramidal & Cerebellar & Brain Stem & $\begin{array}{l}\text { Bladder } \\
\text { Disturbances }\end{array}$ & Age (yr) \\
\hline $\begin{array}{l}\text { Normal sweating response (35) } \\
\text { Abnormal sweating response (25) }\end{array}$ & $\begin{array}{l}2 \cdot 35 \\
3 \cdot 84\end{array}$ & $\begin{array}{l}2 \cdot 26 \\
4 \cdot 20\end{array}$ & $\begin{array}{l}1 \cdot 56 \\
2 \cdot 40\end{array}$ & $\begin{array}{l}0 \cdot 77 \\
1 \cdot 36\end{array}$ & $\begin{array}{l}1 \cdot 0 \\
1 \cdot 76\end{array}$ & $\begin{array}{l}42 \cdot 7 \\
41 \cdot 3\end{array}$ \\
\hline
\end{tabular}


it had to be discontinued after 12 min only. In one subject distension of the bladder by $25 \mathrm{ml}$. water, and in another distension by $100 \mathrm{ml}$. water, was sufficient to set up reflex contractions and emptying of the bladder, but in the others the bladder could accommodate between $250 \mathrm{ml}$. to $450 \mathrm{ml}$. before eliciting a desire to void urine.

POSTURAL HYPOTENSION None of these patients gave a history suggestive of postural hypotension. In four subjects a drop in systolic blood pressure of $20 \mathrm{~mm} \mathrm{Hg}$ or more occurred on changing from the supine to the erect position. In one of these there was almost complete absence of thermal sweating, while in the others normal sweating responses occurred.

\section{DISCUSSION}

Our results suggest that abnormal thermoregulatory sweating responses occur in multiple sclerosis. Thermal sweating is a reflex. The afferent portion of the arc consists of afferent neurones from dermal receptors and warm blood acting on thermosensitive cells in the hypothalamus. The principal centres for regulation of sweating have not yet been located but probably reside in the hypothalamus near the temperature centres. The descending fibres from the hypothalamus and the sympathetic outflow of the thoraco-lumbar cord constitute the efferent portion of the reflex arc. It has been suggested that the cerebral cortex may also have a centre that inhibits sweating (Montagna, Ellis, and Silver, 1962).

Thermal sweating, once it commences, quickly spreads to all areas of the body and the rate of sweating will increase to maximal values within 1-3 hr, after which it may decline progressively (Kuno, 1956). Variations in sweating between different regions of the body may be quite considerable, but as a rough generalization Weiner (1945) estimated that about $50 \%$ of sweating comes from the trunk, about $25 \%$ is derived from the lower limbs, and the remaining $25 \%$ comes from the head and upper limbs.

The pathways linking the hypothalamus with the autonomic spinal motor nuclei of the thoracolumbar cord have been extensively investigated but their location is still disputed. Keller (1938) and Beaton, Leininger, and McKinley (1943) studied temperature regulation and vasomotor function in cats and dogs after section of parts of the brain-stem. They found that pathways subserving heat-loss function appear to be concentrated in the intermediate and lateral part of the dorsal tegmentum of the mid-brain and pons. Magoun, Ranson, and Hetherington (1938) also working on cats discovered that the descending vegetative pathways from the hypothalamus occupy a wide area in both the central and tegmental region of the mid-brain and pass through the medial and lateral portions of the pontile tegmentum. List and Peet (1939) investigated thermal sweating disturbances in patients with lesions of the pons, medulla oblongata, and cervical cord and describe an anatomical outline for these pathways in man. They conclude that the descending sweat fibres decussate in the oral half of the pons, below which they remain ipsilateral and pass through the tegmental region of the pons, the lateral grey matter of the medulla, and the anterolateral and lateral tracts of the cervical cord. Hyndman and Wolkin (1941a), and Johnson, Roth, and Craig (1952) have found abnormalities of thermal sweating and vasomotor function in patients with anterior or anterolateral chordotomy performed for intractable pain. With the former authors this occurred only when the pyramidal tracts were also severed at the time of the operation, while the latter found these abnormalities even though the corticospinal tracts were intact.

Accordingly it appears that these descending autonomic pathways during their course in the brain-stem and spinal cord are not localized but are probably widespread and may be intermingled with several other fibre systems.

It is not surprising that these pathways are involved in multiple sclerosis. In this disease plaques of demyelination are scattered widely and irregularly through the brain-stem and spinal cord. Not uncommonly complete or nearly complete demyelination of a transverse section of the cord can be observed especially in the more severe cases. The degree of axonal preservation within the plaques varies considerably. Greenfield and King (1936) examined histologically 125 cerebral plaques using Bielschowsky's method on frozen sections and found only $10 \%$ showing severe loss of neuro-fibrils. Of the remaining $90 \%$ half showed moderate and half little or no diminution in numbers.

Our failure to demonstrate any spinal reflex sweating after bladder distension is probably related to the persistence of axons within these plaques despite extensive demyelination. Spinal reflex sweating is always pathological and occurs only with severe or complete lesions of the cord. It is a release phenomenon and a component of the spinal mass reflex which is mediated by the distal stump of cord (Head and Riddoch, 1917; List and Pimenta, 1944; Guttmann and Whitteridge, 1947). This degree of severity of damage to the cord is probably not required to produce disturbances of descending autonomic pathways subserving thermoregulatory sweating responses, although our results suggest 
that these disorders occur more commonly in those patients with a more advanced stage of multiple sclerosis. This is in agreement with the findings of Miller et al. (1965) who found that bladder complaints related mainly to the general severity and extent of neurological damage to the spinal cord.

\section{SUMMARY}

The sympathetic nervous system has been investigated in 60 patients by means of the sweating responses to heat, to drugs, and to distension of the urinary bladder.

Abnormal thermoregulatory sweating occurred in 25 patients. In four there was a total, or almost total, lack of sweating, in seven no sweating occurred over the lower half of the body, and in 14 sweating was absent over the lower limbs. These disturbances were commoner in those patients with more severe and advanced multiple sclerosis.

Seven patients, four of them with advanced disease, who also had abnormal thermal sweating responses, were tested for the presence of spinal reflex sweating and it was absent in all of them.

No patient complained of postural hypotension, but in four of those patients whose blood pressures could be recorded in the lying and standing positions a drop in the systolic blood pressure of $20 \mathrm{~mm} \mathrm{Hg}$ or more occurred.

The descending pathways subserving thermoregulatory sweating are described. It is concluded that involvement of these fibres by plaques of demyelination results in impaired thermoregulatory sweating, but the persistence of a large number of axons within these plaques probably accounts for our failure to demonstrate spinal reflex sweating, which occurs only when the distal spinal cord is more or less completely removed from the control of higher centres.

We are grateful to Dr. Hugh Garland, Dr. M.J. Parsonage, and Dr. J. B. Cook, for permission to study and report the patients under their care. M.J.N. and C.J.V. were paid as Research Registrars by the Endowment Fund of the United Leeds Hospitals during the period of this study. We would also like to thank Miss C. L. Brear for secretarial assistance, and she was paid by a grant from the Multiple Sclerosis Society of Great Britain.

\section{REFERENCES}

Beaton, L. E., Leininger, C. R., and McKinley, W. A. (1943). Thermo- $\mathbb{D}$ regulatory pathways in the cat brain stem. J. Neurophysiol., 6, 29-35.

Bors, E., and Comarr, A. E. (1960). Neurological disturbances of sexual function, with special reference to 529 patients with spinal cord injury. Urol. Surv., 10, 191-222.

Dale, H. H., and Feldberg, W. (1934). The chemical transmission of ${ }_{(D)}$ secretory impulses to the sweat glands of the cat. J. Physiol. (Lond.), 82, 121-128.

Edmund, J., and Fog, T. (1955). Visual and motor instability in multiple sclerosis. Arch. Neurol. (Chic.), 73, 316-323.

Greenfield, J. G., and King, L. S. (1936). Observations on the histopathology of the cerebral lesions in disseminated sclerosis. Brain, 59, 445-458.

Guttmann, L. (1947). The management of Quinizarin sweat test. Post grad. med. J., 23, 353-366.

- and Whitteridge, D. (1947). Effects of bladder distension on autonomic mechanisms after spinal cord injuries. Brain, 70, 361-404.

Head, H., and Riddoch, G. (1917). The automatic bladder, excessive $\stackrel{\mathbb{Q}}{\mathcal{D}}$ sweating and some other reflex conditions, in gross injuries of the spinal cord. Ibid., 40, 188-263.

Hyndman, O. R., and Wolkin, J. (1941a). Sweat mechanism in man. $\vec{O}$ Study of distribution of sweat fibres from sympathetic ganglia, $\bigcirc$ spinal roots, spinal cord and common carotid artery. Arch. $\vec{\longrightarrow}$ Neurol. Psychiat. (Chic.), 45, 446-467.

- $-(1941 \mathrm{~b})$. The pilocarpine sweating test. A valid indicator in differentiation of preganglionic and postganglionic sympathectomy. Ibid., 45, 992-1006.

Johnson, D. A., Roth, G. M., and Craig, W. McK. (1952). Autonomic? pathways in the spinal cord. J. Neurosurg., 9, 599-605.

Keller, A. D. (1938). Separation in the brain stem of the mechanisms ${ }_{-}^{-}$ of heat loss from those of heat production. J. Neurophysion, 1, 543-557.

Kuno, Y. (1956). Human Perspiration. Thomas, Springfield, Ill.

Kuntz, A. (1947). Autonomic Nervous System. Lea and Febiger, Philadelphia.

Kurtzke, J. F. (1961). On the evaluation of disability in multigte sclerosis. Neurology (Minneap.), 11, 686-694.

List, C. F., and Peet, M. M. (1938). Sweat secretion in man. I. Swegting responses in normal persons. Arch. Neurol. Psychnt (Chic.), 39, 1228-1237.

- 1 (1939). Sweat secretion in man. V. Disturbances of sweat secretion with lesions of the pons, medulla and cervfatco portion of cord. Ibid., 42, 1098-1127. and Pimenta, A. D. (1944). Sweat

Magoun, H. W., Ranson, S. W., and Hetherington, A. (1938) Descending connections from the hypothalamus. Ibid., 39 1127-1149.

Miller, H., Simpson, C. A., and Yeates, W. Keith (1965). Bladdeñ dysfunction in multiple sclerosis. Brit. med. J., 1, 1265-1269?

Montagna, W., Ellis, R. A., and Silver, A. F. (1962). Advances in Biology of the Skin. Vol. III. Eccrine Sweat Glands and Eccrine Sweating. Pergamon Press, Oxford and New York.

Nelson, D. A., and McDowell, F. (1959). The effects of induced hyperthermia on patients with multiple sclerosis. J. Neurol? Neurosurg. Psychiat., 22, 113-116.

Sulzberger, M. B., and Herrmann, F. (1954). The Clinical Significance. of Disturbances in the Delivery of Sweat. Thomas, Springfield III.

Weiner, J. S. (1945). The regional distribution of sweating. J. Physiot? (Lond.), 104, 32-40. 